\title{
Una comparación entre los idearios políticos fundacionales de ARENA y el FMLN
}

Carlos Mauricio Hernández

Departamento de Filosofía,

Universidad Centroamericana "José Simeón Cañas"

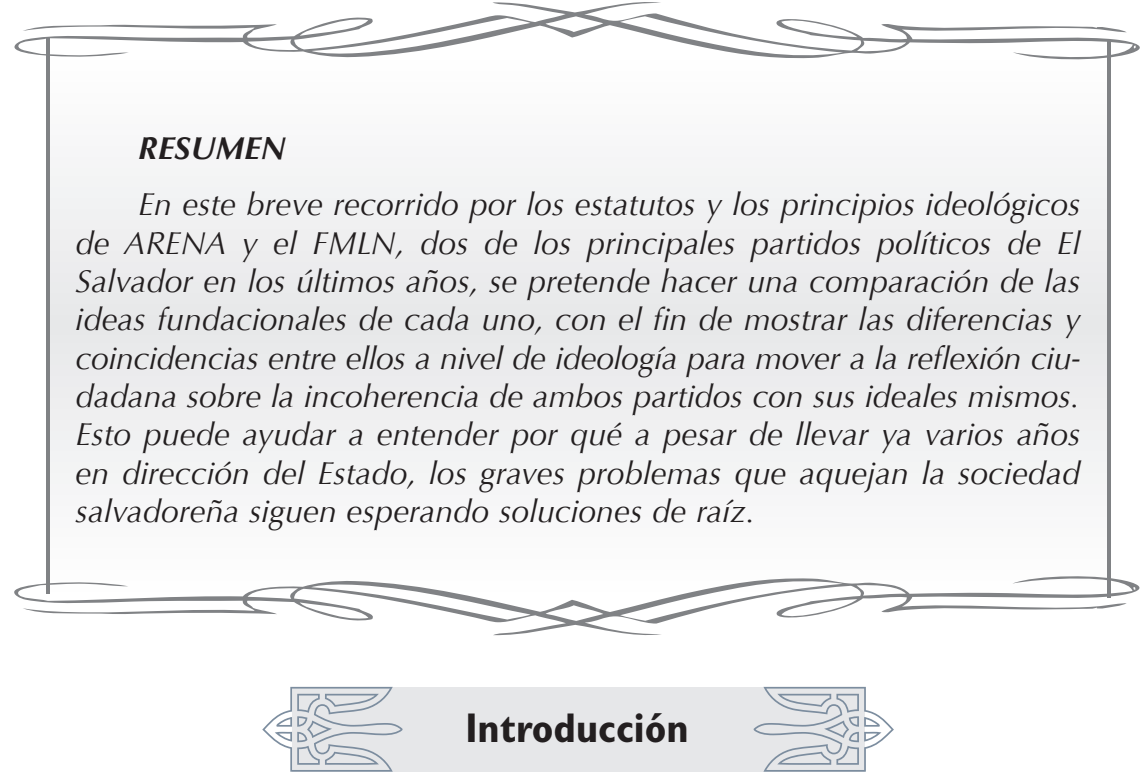

-n este artículo se hace un re- corrido por los estatutos de ARENA y del FMLN ${ }^{1}$ a partir de cuatro ejes -seleccionados a partir del contenido de los mismos- para rastrear aquellas ideas más importantes que constituyen su cuerpo fundacional. Dichos ejes son: a) ideología, b) exaltación de lo local o nacional, c) Derechos Humanos y d) la concepción de democracia.
Se destaca de este análisis que, según los principales aspectos ideológicos, ARENA y el FMLN se ubican en polos opuestos: el primero definido como partido de derecha y el segundo, definido con claridad en la izquierda. ${ }^{2}$ ARENA se constituye en defensa del capitalismo ante la "amenaza" que le supone un movimiento o partido de corte marxista-comunista, mientras que 
el FMLN se autodefine por buscar de manera revolucionaria la transformación radical del sistema capitalista con un derrotero definido: el nuevo orden socialista. Como se ve, si por estos elementos señalados fuera, en El Salvador se estaría en una especie de "Guerra fría" en pleno Siglo XXI. Vale mencionar que el FMLN, hasta esta fecha, no menciona en su ideario político fundacional el Ilamado Socialismo del siglo XXI. Ni ha habido reformas en este sentido.

Sin embargo, a pesar de las discrepancias, muestran coincidencias en defender la democracia, tanto en el capitalismo (ARENA) como en el socialismo (FMLN), así como también en el funcionamiento interno de cada uno de los partidos; en el respeto y la promoción de los Derechos Humanos, ambos partidos hacen una valoración positiva de ellos a tal grado que plantean que su existencia misma se debe precisamente a estos ideales de convivencia humana; y por último, se menciona la coincidencia en la exaltación de lo local o nacional: en ARENA, esto aparece bajo la figura del "nacionalismo" y en el FMLN, con lo que Ilaman "patriotismo". En ambos casos, la aspiración es lograr la unidad nacional. A continuación se presenta un cuadro comparativo que intenta resumir lo que se desarrolla en los siguientes apartados:

\section{Resumen de las ideas principales de los idearios fundacionales de ARENA y el FMLN}

\begin{tabular}{|l|l|l|}
\hline \multicolumn{1}{|c|}{ Eje/ Partido } & \multicolumn{1}{|c|}{ ARENA } & \multicolumn{1}{c|}{ FMLN } \\
\hline A) Ideología & $\begin{array}{l}\text { Derecha: Defensa del sistema } \\
\text { de libertades (capitalismo). } \\
\text { Ataque al socialismo. }\end{array}$ & $\begin{array}{l}\text { Izquierda: Defensa del socialis- } \\
\text { mo = orden justo. } \\
\text { Ataque al capitalismo. }\end{array}$ \\
\hline B) Exaltación de lo local & $\begin{array}{l}\text { Nacionalismo (académica- } \\
\text { mente burdo e impreciso): an- } \\
\text { ticomunismo internacionalista. } \\
\text { Unidad nacional. }\end{array}$ & $\begin{array}{l}\text { Patriotismo: Un partido con } \\
\text { profundas raíces nacionales" } \\
\text { (no aparece "imperialismo yan- } \\
\text { qui"). Unidad nacional }\end{array}$ \\
\hline C) Derechos Humanos & $\begin{array}{l}\text { Partido fundamentado en ellos: } \\
\text { contra totalitarismos violatorios } \\
\text { de los DDHH. }\end{array}$ & $\begin{array}{l}\text { Partido inspirado en la defensa } \\
\text { y promoción de ellos: contra } \\
\text { políticas de Estado y del mer- } \\
\text { cado violatorios de los DDHH. }\end{array}$ \\
\hline D) Democracia & $\begin{array}{l}\text { Pro democracia = anti revolu- } \\
\text { ción. Funcionamiento interno } \\
\text { democrático. Participación de } \\
\text { la mujer }\end{array}$ & $\begin{array}{l}\text { Pro democracia = en revolu- } \\
\text { ción. Funcionamiento interno } \\
\text { "altamente" democrático: el } \\
\text { debate es "amado". Participa- } \\
\text { ción de la mujer }\end{array}$ \\
\hline
\end{tabular}

Fuente: Elaboración propia con base en los estatutos y carta de principio de ARENA y el FMLN. 
La información del cuadro anterior se encuentra en los documentos utilizados para considerar los planteamientos fundamentales de ARENA: los Estatutos del partido "Alianza Republicana Nacionalista", los Principios ideológicos y objetivos y en el Manual del activista. En el caso del FMLN, para examinar su ideario primario se utilizaron dos documentos: Ios Estatutos del partido FMLN y la Carta de principios y objetivos. Veamos a continuación los cuatro ejes arriba mencionados para efectos de la comparación estipulada.

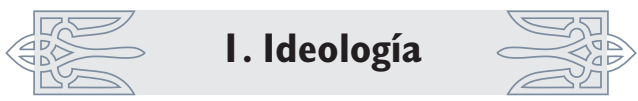

\subsection{ARENA}

Ideológicamente el principal partido que se define de derecha en el espectro político salvadoreño es ARENA. Lo que en última instancia define su postura es lo que consideran el gran peligro para el país: el llamado comunismo. La argumentación sigue de la siguiente manera: el comunismo está en contra del nacionalismo y de todos los valores propios de la patria, pero sobre todo de la libre empresa que garantiza la mejor manera de organizar la vida social, política y económica. Por tanto, es necesario derrotarlo para salvar a la patria y su orden institucional, ya que aquella ideología (el comunismo) se basa en el marxismo-leninismo cuyo horizonte es instaurar en el mundo un sistema no capitalista que irrespetaría los Derecho Humanos y, por ende, al individuo y su derecho a la libertad empresarial. En el último de sus principios ideológicos, ARENA plantea con toda claridad su antagonismo:

Rechazamos todas aquellas doctrinas que pregonan la lucha de clases; defendemos nuestro sistema democrático, republicano y representativo, ante la penetración ideológica y la agresión permanente del comunismo internacional. ${ }^{3}$

El gran peligro de la doctrina comunista estriba en que plantea terminar con la lógica capitalista de la libre empresa; de ahí que este partido se autoconcibe pro empresarial, acérrimo defensor del sistema de libertades que permite al mercado actuar de manera libre y garante que el Estado no se inmiscuya más de la cuenta en ese tipo de asuntos, sino que adopte un sistema económico "orientado hacia el incremento de la productividad, a través de la libre empresa, cuyos principios deben ser respetados e impulsados por el mismo". ${ }^{4}$ Es natural, entonces, que la relación con la empresa privada, sobre todo con la grande, sea de cordialidad y de apoyo explícito, y no es extraño que los grandes empresarios locales e internacionales hayan hecho de 
ARENA su partido político durante muchos años, no sólo como simples militantes o activistas sino como dirigentes de alto rango.

Por otro lado, ser de derecha en El Salvador le exigió a este partido considerar a la Fuerza Armada como un aliado importante para el sistema de libre empresa, sobre todo al tener presente el contexto de guerra civil en el que nació ARENA. La legitimidad de constituir en el país una organización armada le corresponde exclusivamente al ejército nacional:

Se reconoce a la Fuerza Armada Salvadoreña, como único brazo armado del pueblo; y como tal, merece total apoyo y reconocimiento en el cumplimiento de sus deberes constitucionales. $^{5}$

Así expresa el principio ideológico número once la relación entre ARENA y la Fuerzas Armadas de El Salvador. Rechazan todo tipo de movimiento armado que no esté bajo la tutela institucional de esta institución; y en el objetivo tres de sus principios ideológicos agrega y recalca lo que se ha señalado en la anterior cita sobre la Fuerza Armada del país:

Apoyar a la Fuerza Armada en el cumplimiento de sus deberes constitucionales, como son la defensa de la integridad territorial, la soberanía de la república, el mantenimiento del orden público; y en la acción contra todo movimiento subversivo que atente contra la seguridad nacional. ${ }^{6}$

El partido de derecha concibe así que su relación con esta institución castrense es de respeto y de apoyo. En la lucha contra los Ilamados terroristas, marxistas y todo tipo de arengas contra cualquier "subversivo", 7 la FAES está ahí como una aliada de esa lucha frontal, sin entrar en detalles acerca de si debe o no ser una institución apolítica, tal y como se definió después de los Acuerdos de Paz.

\subsection{FMLN}

El partido político de izquierda tiene como una de sus ideas más importantes la lucha que haga cambiar la realidad del país para crear una sociedad más justa. Esa lucha implica una transformación radical. Según Medardo González, coordinador general del FMLN, esa fue la meta por la cual lucharon por la vía armada durante la guerra civil salvadoreña y por la cual seguirán luchando ya desde otra trinchera, la electoral: 
Nuestra Carta de Principios y Objetivos; y nuestros Estatutos, guían nuestra manera de forjarnos como hombres y mujeres nuevas, servidoras del pueblo, transformadoras de la sociedad, luchadoras y luchadores sociales por una cultura democrática participativa que nos permita alcanzar los cambios necesarios y justos. ${ }^{8}$

El horizonte hacia el cual se orienta la lucha transformadora de la realidad salvadoreña es un sistema de organización social, económica y política que, según este partido, está más allá de la lógica del sistema capitalista. Es decir, se

trata de una lucha que transforme al país de ser capitalista a un sistema totalmente opuesto. De ahí que el derrotero hacia el cual se debe dirigir el país para alcanzar los cambios necesarios y justos en beneficio del pueblo es el sistema socialista:

El Frente Farabundo Martí para la Liberación Nacional es un Partido Político democrático, revolucionario y socialista; de lucha permanente, que busca aglutinar y defender los intereses de las grandes mayorías populares y de las fuerzas democráticas y progresistas. ${ }^{9}$

Al parecer, en el párrafo citado se equipara el bien común con los intereses de las mayorías populares $y$, a su vez, aparece relacionado el socialismo con la transformación radical o revolucionaria del sistema capitalista:

Se fundamenta en la existencia y fortalecimiento constante de un interés político común basado en su Carta de Principios y Objetivos, en su programa y en la unidad básica de su pensamiento enriquecida con la diversidad propia de una izquierda democrática, revolucionaria y socialista. ${ }^{10}$

Ese bien común, la caída del capitalismo (con todos sus males atribuibles: muerte, miseria, injusticia, desorden social, etc.) y la implantación del socialismo (y todos sus beneficios atribuibles: vida digna, justicia, orden social adecuado para el respeto de la integridad humana) sólo serán posible si se lucha por transformar esta realidad.
El FMLN asume en sus estatutos que para lograr la nueva sociedad, la lucha electoral es fundamental. Esto implicó una renuncia a la lucha armada como la clave para lograr el objetivo final del partido de izquierda.

Como ya se mencionó arriba, la transformación de la realidad po- 
lítica, social y económica planteada por el FMLN implica hacer una revolución. En el principio número cuatro, este partido electoral esta- blece una combinación entre lucha radical por transformar la realidad salvadoreña (revolución) y la forma de gobierno llamada democracia:

La construcción de una sociedad democrática en los órdenes político, social y económico constituye la razón de ser de nuestro Partido. Ello supone una transformación de alcances estructurales, y una actividad social y política de carácter revolucionaria orientada a ese fin. ${ }^{11}$

Dicha revolución, pues, tiene como base la crítica que recae sobre el sistema capitalista el cual se necesita cambiar por el socialista. Se argumenta en este sentido que:

Para alcanzar la liberación plena de la sociedad salvadoreña se necesita la recuperación, conservación y desarrollo del medio ambiente, ahora degradado por la irracionalidad y anarquía del sistema económico-político imperante, que privilegia el afán de ganancias económicas por encima del interés común. ${ }^{12}$

Finalmente, en el objetivo número ocho se expresa la utopía del FMLN con respecto de la sociedad salvadoreña. Aparecen ahí todos los elementos ideológicos primordiales en forma de síntesis sobre la con- cepción de lucha, transformación, democracia, socialismo, que tienen como fin último crear una nueva y mejor sociedad (fruto exclusivo del socialismo):

Ese sistema estará basado en los postulados esenciales de libertad, justicia, humanismo, solidaridad, igualdad y equidad de género, equidad económica y participación democrática, orientada a superar la explotación y la marginación entre las personas, de una minoría sobre la mayoría y/o del Estado o del mercado sobre el conjunto de la sociedad... El Socialismo así, habrá de realizar el desarrollo humano sostenible. ${ }^{13}$

De esta manera queda clara la relación antagónica con los partidos de derecha o de cualquier otra índole que no se plantean una revolución socialista. Ahí está su énfasis en la diferencia específica respecto de cualquier otro partido. Se trata pues de profundizar en una práctica diferenciable que inspira el quehacer de todo militante, pues 
debe "actuar con base a los valores y principios de la ética revolucionaria, diferenciándose de la práctica oportunista y mentirosa de los políticos tradicionales". ${ }^{14}$

El sistema electoral salvadoreño antes del aparecimiento del FMLN, según la lógica de este partido, se caracterizaba por estar compuesto de políticos que no buscaban el bienestar común, sino aprovecharse de los cargos público y mentir en las campañas electorales constantemente al electorado. La ética revolucionaria es planteada como lo propio del FMLN en relación con los demás partidos. Ella haría que de llegar a cargos públicos, el Estado realmente se ponga al servicio del bien común y caminar así a la transformación radical del orden establecido.

En conclusión, para el FMLN, la única medicina posible para resolver los grandes males de $\mathrm{El}$ Salvador es el socialismo, entendido como una forma de organización de la sociedad en todos sus niveles que se orienta por la búsqueda de la justicia y el bien común en lo económico, lo político, lo jurídico y social. Vale preguntarse para cerrar este apartado: ¿qué tan fieles a la ética revolucionaria han sido los diferentes alcaldes, diputados y demás funcionarios públicos del FMLN en los años de estar en sus cargos? Similar pregunta se haría con respecto de ARENA y su defensa del individuo y la productividad del país. La respuesta no es de ninguna manera fácil de dar. Es más bien una tarea por realizar. Aunque la pregunta de fondo es la que sintetiza cualquier cantidad de interrogantes que se pudieran elaborar: ¿qué tan fieles a sus estatutos o a sus idearios fundacionales han sido las personas que han ocupado puestos del Estado que se declaran del partido de derecha o del Frente? A continuación otro elemento de coincidencia y poca precisión que nos llevaría a la anterior pregunta.

\section{La exaltación de lo local o nacional}

\subsection{ARENA}

Una de las ideas más importantes del ideario del partido ARENA que aparece recalcado en sus documentos es el nacionalismo, aunque el uso que se le da es ambiguo, pues no se trata de una definición precisa. ${ }^{15}$ Uno de los fundadores del partido ARENA, Roberto D'Aubuisson, afirma que se puede determinar quién es nacionalista puro de la siguiente manera:

Nacionalista puro es el que nunca busca elogios, el que descubre que es mejor dar que recibir, el que en su vida tiene como abogado al Señor y después como juez al tiempo, 
el que ama a su patria y se entrega a defenderla... Primero El Salvador, Segundo El Salvador, Tercero El Salvador... Que Dios los bendiga. ${ }^{16}$

En esta frase del líder arenero está condensada la concepción de nacionalismo manejado por este partido político sin definir a la nación con rasgos étnicos, sino que se plantea como una entidad política. De esta manera, el nacionalismo se concibe como la doctrina que le da sentido a la práctica personal de tener amor por la patria. Se plantea así la nación de "El Salvador" como una entidad a la cual hay que defender de cualquier agresión de grupos extraños o extranjeros, sin faltar la alusión a una divinidad como elemento indispensable de este nacionalismo. Según ARENA, el nacionalismo es producto de la na- ción. No plantea que, en realidad, el nacionalismo es una ideología que busca construir el imaginario entorno de una nación.

El respeto por los símbolos patrios es otro de los elementos importantes de este discurso nacionalista. El artículo 104 de los estatutos del partido de derecha señala que es obligación entonar el Himno Nacional y luego la marcha de ARENA en toda actividad partidista. De hecho, el artículo 105 manda que se exprese con acento el hecho de estar presente por esta patria a la cual hay que defender de todo peligro:

Para efectos de las tomas de Potestad de los miembros de cualesquiera de los Organismo del Partido, estos protestarán alzando la mano derecha y expresando en voz alta la frase: PRESENTE POR LA PATRIA. ${ }^{17}$

El énfasis de estar "presente por la patria" está muy ligado a lo que D'Aubuisson planteaba repitiendo que la patria o la nación de El Salvador debe estar en primero, segundo y tercer punto de prioridad simultáneamente. Esta ideología nacionalista cruza todas las demás ideas que son los fundamentos ideológicos del partido, como la idea de democracia, la paz, la libertad, los enemigos de la patria, etc.:

La lucha nacionalista del arenero se fundamenta en la moral del trabajo, sin ligarnos con la palabrería de ideologías marxistas o comunitaristas de carácter internacional, que no hacen otra cosa que explotar en el mundo las miserias de las masas. Con fe en nuestra dignidad nacional luchamos por alcanzar la paz, el progreso y la libertad. ${ }^{18}$ 
Aquí aparece un elemento típico del nacionalismo que parte de una idea de nación étnica o cultural: amigo/enemigo. En este caso se refiere a todo lo que tenga relación con ideas marxistas o cualquier postura que vaya en contra del individualismo. El comunismo, en este sentido, aparece no como un fantasma, sino como un monstruo extremadamente peligroso para la seguridad nacional que hay que combatir hasta eliminarlo. Por ello, cuando en ARENA se habla de la dicotomía nacional-internacional, se refiere a que los grupos marxistas pretenden eliminar la soberanía nacional y los valores propios del país para adherirlo a la Internacional Socialista. Eso representa un atentado al orden público. El camino que queda es enfrentar al enemigo de la patria y cuidar así el individuo como centro de toda actividad del Estado y sobre todo a la libre empresa, ya que ésta es la única manera de hacer que el país progrese.
Finalmente, se presentan algunos lemas que expresan lo que consideran su ideología nacionalista. La carta de principios finaliza con las siguientes consignas: "El partido de la salvación nacional", "El que no tenga patria, que la busque, el que la tenga, que la defienda", "Hoy lucha, mañana paz, progreso y libertad". ${ }^{19}$

En todos estos lemas aparece de fondo la idea del nacionalismo, a tal grado de afirmar que ARENA es el partido político que salvará al país de cualquier peligro, que en la lógica de este partido, el mayor de los peligros lo representa todo movimiento subversivo del orden público establecido de libre empresa y libertad individual. De ahí que una de las características que un activista debe tener, según ARENA, es la inteligencia, que consiste en:

Tener la facultad de conocerse a sí mismo y conocer el mundo exterior; de conocer los valores y saber distinguir entre lo bueno y lo malo, lo justo y lo injusto, lo bello y lo feo, conocer qué es ARENA y quién es nuestro enemigo. ${ }^{20}$

Dentro de las misiones del activista arenero está hacer crecer el nacionalismo y convencer de que ARENA es el único "instrumento" político capaz de lograr el desarro-
Ilo nacional, la consolidación de la paz y el cuido de la libertad. ${ }^{21}$ De esta manera, el arenero aporta a la "salvación nacional":

Haciendo llegar la ideología nacionalista a todas las personas, en todos los barrios, en todos los cantones y en todas las ciudades de cada uno de los departamentos de El Salvador. ${ }^{22}$ 
Estrechamente relacionado con el nacionalismo, se plantea el tema de la seguridad nacional. En el tercero de sus objetivos, ARENA ex- presa que busca apoyar a la Fuerza Armada frente a peligros de "internacionalistas" que atentaran contra la patria:

Apoyar a la Fuerza Armada en el cumplimiento de sus deberes constitucionales, como son la defensa e integridad territorial, la soberanía de la república, el mantenimiento del orden público; y en la acción contra todo movimiento subversivo que atente contra la seguridad nacional. La seguridad nacional, tendrá plena vivencia dentro de un Estado de Derecho... La seguridad nacional, será el reflejo de la participación cívica del pueblo en los problemas nacionales, de conservar y ampliar la cultura, la educación y la moral para desarrollar así la personalidad del salvadoreño en los valores del mundo occidental. ${ }^{23}$

La seguridad nacional se pone en función de cuidar y mantener lo que, según este partido, es el orden público establecido. Esto es un mensaje contra todo esfuerzo por transformar de manera radical la sociedad salvadoreña. Esta idea supone que el orden establecido es el mejor y que no puede haber otro que le supere, por tanto, cambiarlo sería un error contra los valores de occidente relacionados sobre todo con el cuido de la libertad individual. Se recalca así que la seguridad nacional es respuesta a la agresión comunista que está en contra de los valores y principios occidentales de respeto al individuo, a la gran empresa, a la religión, al Estado y las diferentes expresiones culturales propias de la patria. En el objetivo número uno se plantea esta idea:

Defender nuestras tradiciones occidentales ante el ataque ideológico y agresión permanente del comunismo internacional, y frente a otras ideologías y organizaciones políticas que pongan en peligro la vida Institucional de El Salvador: adoptando para esto tres principios: nacionalismo, democracia y libertad. El nacionalismo: como la ideología que nos garantizará la estructura social adecuada a nuestro pueblo. Entiéndase como el ideal de un pueblo que aspire a tener política propia, tener un Estado propio que se componga de todos sus connacionales. ${ }^{24}$

Aparece aquí con fuerza la exaltación de lo local, que puede incluso considerarse folclórica de "lo nuestro". En esta misma línea, el 
artículo uno de sus estatutos afirma que se trata de un partido en el que la democracia, el sistema econó- mico que defiende y promueve la libre empresa y el nacionalismo, son inseparables:

El partido Alianza Republicana Nacionalista, que se puede identificar con las siglas ARENA; es una Institución Política de carácter permanente constituida por Salvadoreños que defienden el Sistema de Gobierno Democrático, Republicano y Representativo; el Sistema Económico y Social de Libre Empresa y el Nacionalismo. ${ }^{25}$

La libertad, tanto empresarial, de mercado y la del individuo, es uno de los principios más proclamados por este partido político de derecha. De ahí que hasta en el lema se exprese este principio, tal como se plantea en el artículo siete de los estatutos: "PAZ, PROGRESO
$Y$ LIBERTAD". ${ }^{26}$ En los primeros tres principios ideológicos de ARENA se plantea que tanto la democracia como el Estado deben de estar en función del individuo. El argumento de fondo es que sólo en la medida que se vele por el individuo será posible el progreso del país:

(1) El sistema democrático, republicano y representativo, que garantice la libertad de acción y consecución de fines pacíficos del individuo, es la vía más rápida y estable para lograr el desarrollo integral de la nación.

(2) Se reconoce al individuo como la base fundamental del pueblo, y la familia como el núcleo fundamental de la sociedad.

(3) El Estado no es un fin en sí mismo, sino que el medio para el engrandecimiento y superación del individuo. ${ }^{27}$

Se plantea aquí un último aspecto relacionado con el nacionalismo: la llamada unidad nacional. Según el objetivo tres de la carta de principios y objetivos de ARENA, ello se logrará con la creación de una conciencia nacionalista. El objetivo número dos plantea que se debe:

Luchar por la formación de una sólida conciencia republicana y nacionalista que sea el pedestal de la unidad nacional y permita realizar bajo una misma dirección, el desarrollo integral que el país necesita, logrando a su vez restaurar 
los valores permanentes de nuestra civilización. La unidad nacional: será el resultado de la participación del pueblo en lo político, económico y social, mediante su organización en los diferentes sectores. ${ }^{28}$

Su concepción de unidad nacional hace referencia a que el país tenga un rumbo adecuado, de manera "integral", acompañado este rumbo que lleva al desarrollo de valores y principios propios de la civilización occidental que ARENA defiende. En esta lógica, el partido de derecha no está en contra de que las personas participen activamente en la política, pues es condición indispensable para lograr el rumbo que permita el desarrollo integral. Las personas deben de organizarse e incidir así en lo social, económico y en lo político, siempre y cuando lo hagan con una conciencia "nacionalista". Esta unidad nacional crearía beneficios a toda la población, a tal grado que eliminaría la pobreza en todas sus formas:

La unidad nacional, se consolidará, dentro de una sociedad libre donde todos los ciudadanos actúen en términos reales, desarrollando sus capacidades personales, encontrando, tanto en la sociedad como en el Estado, el apoyo necesario para que a través de este esfuerzo, logremos erradicar la pobreza espiritual, cultural y material existente... Nuestro partido estimulará la unidad nacional, propiciando la igualdad de oportunidades y velando por el respeto a los símbolos patrios. ${ }^{29}$

En este ideario político, la pobreza y falta de oportunidades son concebidas como fenómenos a superar con la unidad nacional promovida desde el nacionalismo. La igualdad aparece como un ho- rizonte ético o principio abstracto al cual se recurre para plantear el imaginario de cómo sería una sociedad; y aunado al tema de la unidad nacional, ARENA considera la unidad centroamericana:

Como país occidental, buscaremos el fortalecimiento de nuestra área al propiciar por todos los medios a nuestro alcance, la unidad de Centro América, a través de la formación de una confederación de Estados, garantizando siempre la idiosincrasia nacionalista de cada uno de sus miembros. ${ }^{30}$ 
La anterior cita es el principio ideológico doce en donde expresa el deseo de construir no sólo la unidad nacional sino de toda Centroamérica. Aunque no profundiza mucho, al parecer se está a favor de esa unidad porque tendría los mismos beneficios que la unidad nacional. La unión centroamericana implica que cada país sea nacionalista.

\subsection{FMLN}

Si ARENA habla de nacionalismo para exaltar lo local, el FMLN utiliza un término diferente -patriotismo-, aunque en el fondo ser refieren básicamente a lo mismo. El último de los literales del artículo cinco de sus estatutos, donde se menciona los principios del militante de este partido político, afirma lo siguiente: "Centroamericanismo, patriotismo y solidaridad entre los pueblos". ${ }^{31}$ Para este partido tener como principio ideológico el patriotismo, y todo lo que ello implica, es un concepto que roza en su connotación con términos como: defensa nacional ante amenazas extranjeras a la nación o patria salvadoreña, soberanía nacional, unidad nacional, entre otros. En el principio partidario número seis, el FMLN plantea su contenido patriótico de fondo en la lucha por transformar a El Salvador:

La independencia nacional y libre determinación de los salvadoreños es la primera condición para una democracia auténtica. La soberanía descansa en voluntad consciente del pueblo salvadoreño. Históricamente, el FMLN es un partido de raíces nacionales muy profundas. ${ }^{32}$

Como ejemplos de ese patriotismo, en el mismo principio se ponen como ejemplos históricos de la raíz nacional del Frente, el espíritu combativo que tuvieron los antepasados salvadoreños en su lucha frente a agresiones extranjeras como la española, la acción de sublevación de los Nonualcos, lo que ellos Ilaman "la gesta liberal" de independencia y unificación centroamericana, la insurrección campesina de 1932 y toda la lucha antidictatorial y antimilitar durantes los años posteriores, teniendo como culmen la lucha armada que se dio durante la guerra civil salvadoreña de la década de 1980. Todo ello es ejemplo de que el FMLN no pretende eliminar todo lo relacionado con la idea de nación salvadoreña creada culturalmente desde años remotos.

En consonancia con esta idea, en el artículo ochenta y cuatro se menciona que serán miembros honorarios del partido aquellos que tengan méritos patrióticos, cívicos, democráticos, científicos o profesionales. ${ }^{33}$ Además, la patria o la nación de El Salvador es por la cual se debe dar la vida ante cualquier peligro extranjero. De ahí que se tenga como un objetivo importante el rescate de la identidad nacional: 
Recuperar la soberanía y fortalecer la independencia nacional, basados en la autodeterminación de los salvadoreños, a fin de promover y desarrollar la democracia y nuestra verdadera Identidad nacional, en un marco de relaciones internacionales de cooperación, amistad y respeto mutuo. ${ }^{34}$

En el objetivo antes citado, no solamente se habla de la identidad nacional, sino que se le coloca el adjetivo de "verdadera", al igual que cuando ARENA menciona que existe un "verdadero pueblo salvadoreño". En este punto, pues, ambos partidos coinciden en buscar servir o rescatar al "verdadero" pueblo salvadoreño y su "verdadera" identidad.
La construcción de la identidad nacional es parte, según el objetivo once del FMLN, del quehacer concreto de este partido, muy relacionada esa acción con principios como la paz, la justicia y hasta incluso en relación con los valores cristianos:

El rescate y fortalecimiento de los valores históricos de la nación: su identidad nacional, el unionismo centroamericano, su tradición de lucha por la justicia, la libertad, la soberanía, la democracia, la paz, el humanismo social, los valores morales del cristianismo que inspira a la mayoría de la población... son una guía en el pensamiento y quehacer del FMLN. ${ }^{35}$

No obstante, el partido de izquierda no considera que la verdadera identidad nacional se construya en detrimento de relacionarse con otras culturas o países de la región o del mundo. Por ello, se debe luchar por la identidad nacional, pero sin convertirse en una isla, sino más bien crear vínculos o lazos de relación con otros países bajo las reglas básicas de respeto mutuo; y por ello es que para el FMLN la unidad de Centroamérica está dentro de sus quehaceres. Los principios de fondo son los de solidaridad, respeto, cooperación y amistad con otros países de la región y del mundo:

El FMLN está orientado por un acendrado sentido de solidaridad con los pueblos, e identificado de manera muy particular con la lucha de las naciones del sur por un nuevo orden internacional, económico, social y político, basado en relaciones de respeto, cooperación y amistad entre todas las naciones del mundo. La actividad del FMLN está fundada en un espíritu centroamericanista que favorece los procesos 
de democratización y desmilitarización, lo mismo que los esfuerzos integracionistas que propicien el desarrollo y la estabilidad regional. ${ }^{36}$

Al parecer, este partido distingue dos tipos de relación con países extranjeros en relación con la identidad nacional. La primera sería negativa, estaría todo aquello que tiene que ver con intervencionismo, irrespeto a la soberanía nacional y por sobre todo, lo peor, sería el imperialismo, aunque no lo diga explícitamente. El segundo tipo de relación con países extranjeros, los coloca en términos positivos de amistad, respeto y cooperación que conlleven un desarrollo mutuo, sin imponer nada ni involucrarse en

situaciones que generen perjuicios a un país en beneficio de otro.

En este sentido, el FMLN está en la línea de crear otro orden internacional de relaciones entre países. Sin embargo el tema de la integración centroamericana, un sueño de muchas personas desde hace varios años atrás, es un asunto que el Frente lo considera muy apremiante para el desarrollo nacional y regional. Pero antes debe haber unidad nacional.

El FMLN es un partido comprometido en el esfuerzo de la reconciliación y la unidad nacional en democracia, a fin de profundizar la paz y alcanzar el progreso. El FMLN favorece a los recursos de diálogo y la concertación como una manera racional y humana para resolver las diferencias sociales y políticas. ${ }^{37}$

Al igual que ARENA, el FMLN tiene como principio ideológico crear condiciones que propicien el diálogo entre los diferentes sectores del país, que más allá de sus diferencias políticas o de otro tipo, se unan para construir juntos un nuevo y mejor El Salvador. Esta es una fuerte coincidencia que aparece en los principios ideológicos de ambos partidos que en la arena electoral se presentan en dos polos extremos. Tal es el caso de las llamadas libertades. El Estado en esta exaltación de lo local no debe eliminar el derecho arriba mencionado:

El FMLN favorece la vigencia plena de todas las libertades ciudadanas, entre las que propiciaremos de manera especial la libertad de expresión, lo mismo que la libertad de culto y el respeto profundo a las tradiciones y creencias religiosas. ${ }^{38}$ 
Como se ve, no es un Estado "internacionalista" que busque la unidad centroamericana en contraposición de lo que se pudiera llamar -también folclóricamente"lo nuestro", sino que, al contrario, las tradiciones locales deben ser respetadas al igual que todo tipo de creencias religiosas locales.
Finalmente, el FMLN plantea que la izquierda no se reduce a un partido político, sino que hay "fuerzas" sociales que comparten el ideal de construir una mejor sociedad salvadoreña, más justa, igualitaria, en una palabra, en socialista. Así se plantea en el siguiente principio:

Compromiso con la unidad de las fuerzas del pueblo y de concertación desde la izquierda, con las demás fuerzas democráticas, patrióticas y progresistas de la sociedad, que permita la solución de problemas y la más amplia confluencia política, social y económica por el cambio. ${ }^{39}$

Transformar la realidad de manera radical implica hacer alianzas estratégicas que permitan el cambio de sistema deseado. Esa lucha se debe hacer desde varias áreas: desde el poder del Estado, desde los movimientos sociales de cualquier tipo, siempre y cuando tenga una coincidencia de transformar la sociedad en una mejor.
Así pues, el partido de izquierda tiene en sus idearios la exaltación de lo local sin duda alguna, complementado con su propuesta de luchar por una unidad nacional, unidad Centroamericana, pero también la unidad de las izquierdas que logren un Estado justo que sea respetuoso de expresiones folclóricas propias de la idiosincrasia del país.

\section{Derechos humanos}

\subsection{ARENA}

En el artículo tres de sus estatutos, ARENA menciona que se trata de un partido en sintonía con los derechos humanos y, por tanto, contra todo tipo de régimen político que no cumpla con los postulados básicos de la carta magna sobre los mismo:

El Partido Alianza Republicana Nacionalista, rechaza las tesis Políticas Totalitarias. Es un Partido constituido de conformidad con nuestras leyes, con el espíritu de fraternidad regional y continental, y fundamentado en la Declaración Universal de los Derechos Humanos. ${ }^{40}$ 
La Declaración Universal de los Derechos Humanos sería así un referente en los principios ideológicos de ARENA. No los consideran un estorbo al progreso de la nación, sino que aparecen como un horizonte ético para la acción política. En su lógica, un sistema socialista, propugnado y defendido por el FMLN, está totalmente reñido con lo estipulado por los Derechos Humanos.
Sólo en un sistema de libertades, los mismos estarían asegurados.

\subsection{FMLN}

Al igual que ARENA, los Derechos Humanos son un referente infaltable en su visión ideológica. En el principio número uno, el FMLN afirma que asume, respeta y promueve los Derechos Humanos en el país:

La humanización profunda de las relaciones en la sociedad, de su sistema económico, social y político, es el fin de las transformaciones, el progreso y la paz que se propone el FMLN. Nos adherimos a la Declaración Universal de los Derechos Humanos y estamos comprometidos en su desarrollo. ${ }^{41}$

Además se señala como condición necesaria el cumplimiento de

Ios Derechos Humanos para hablar realmente de democracia:

Alcanzar la vigencia, desarrollo y garantía de los Derechos Humanos en la sociedad salvadoreña, como una condición indispensable para la convivencia pacífica, la democracia y el desarrollo nacional. ${ }^{42}$

Los Derechos Humanos son planteados también por el FMLN como un horizonte ético que constituyen una condición sin la cual tanto la democracia, como el desarrollo social y el socialismo no pueden darse en la práctica, caso contrario con el capitalismo, el sistema que -en la lógica del FMLN-
ARENA defiende y procura, pues por su índole tiende a favorecer a una minoría en detrimento de los derechos fundamentales o básicos para la gran mayoría de la población, lo cual hace que la relación capitalismo-derechos humanos sea totalmente incompatible. 


\section{Democracia}

\subsection{ARENA}

Antes se ha mencionado que ARENA asegura defender un sistema democrático representativo y republicano, rechazando cualquier sistema que apunte al totalitarismo y dictaduras personales. El voto es considera el arma de los hombres li- bres y las elecciones, en general, el acto de legitimación por excelencia de quien asume un cargo público. En este sentido, ARENA se considera como un partido estrictamente democrático. Y por tanto defensor de un modelo de ejercer la política democrático. Afirma que el poder reside y viene de la

Soberanía del pueblo mediante el ejercicio libre del sufragio y con la dinámica necesaria en la aplicación de los poderes que tiene el pueblo para sostenerla los cuales son: (1) El poder de elección, (2) El poder de sustitución, (3) el poder de iniciativa y (4) el poder de referéndum. ${ }^{43}$

Parece ser que ARENA entiende la importancia de las elecciones para hacer efectiva y funcional la democracia. Empero, en el Manual del activista menciona otras características que van más allá de los procedimientos formales de elección a cargos públicos:

Democracia es poder decidir libremente lo que pensamos y queremos, sin destruir el prestigio, la honra y los derechos de los demás, sin atentar contra la moral y las buenas costumbres. Democracia es criticar al Gobierno sin tener presiones. Democracia es no poder ser detenido o apresado sin tener una orden judicial, todo eso es Democracia. ${ }^{44}$

Esa práctica democrática debe ser también interna. Así lo expresan en el artículo ciento dos de sus estatutos:

Las estructuras del Partido, se basan en el principio de elección popular, Dirección Centralizada y Ejecución Descentralizada, reconociéndose como derecho de ser miembros y organismos los Principios Democráticos de crítica y autocrítica interna. ${ }^{45}$

La democracia interna propiciaría de esta manera un espacio adecuado para la crítica o auto crítica en la medida en que se comentan errores. 
Para finalizar este apartado, se coloca un ítem con respecto de la participación femenina. A pesar de que no hay muchas referencias directas de la visión de ARENA sobre ello, se menciona en los estatutos al "Sector Femenino" como uno de los entes productivos para la promoción humana y el desarrollo político, económico y social del país. ${ }^{46}$ Por otro lado, en el Manual del activista, se menciona la actitud que debe tener el arenero que llegue a visitar a una familia en el campo:

En el medio rural las visitas deben hacerse cuando el jefe de la familia está en casa, no debo dirigirme directamente a la señora, sino plantear la conversación que envuelva a la familia. ${ }^{47}$

Lo anterior muestra que, en el ideario de ARENA, se parte del supuesto que en el campo o zona rural la situación del machismo es un elemento a considerar seriamente. Ahí la situación de la mujer es de inferioridad y por tanto, como estrategia electoral, a quien se debe convencer es al hombre, en tanto que "jefe de la casa" o de la familia. ¿Es esto jugar con el machismo o alimentarlo? En la lógica arenera es lo primero; pero críticamente, la consecuencia es que alimenta la concepción machista de inferioridad de la mujer.

\subsection{FMLN}

Según el ideario del FMLN, democracia no es un concepto que se deba reducir a un procedimiento cuya esencia está en la elección de cargos públicos de parte de la demás población de ciudadanos que no optan por ellos. La lucha revolucionario implica el establecer no sólo una democracia en sentido "formal", sino una democracia real, tal y como la mencionan en su principio nueve (que habla sobre igualdad de género): "Este es un principio fundamental en la edificación de la democracia real y en la construcción de la sociedad socialista por la que lucha el FMLN". ${ }^{48}$ Así pues, los elementos que componen una democracia (real, más allá de una formal) son los que se mencionan a continuación:

Construir una democracia política real y participativa, en el que los ciudadanos puedan disfrutar de todas las libertades políticas y ejercer sus derechos, especialmente su derecho a elegir o revocar libremente a sus gobernantes, el derecho a una correcta administración de justicia... el derecho a las libertades de asociación, a la libre expresión y a la libertad de credo y religión, lo mismo que el ejercicio de todas las 
libertades fundamentales que posibilite el goce pleno de sus derechos. ${ }^{49}$

Pero esta democracia no se reduce a lo que el objetivo tres, anteriormente citado, ha planteado. Tanto la economía como en general todo lo relacionado con prácticas sociales deben estar impregnadas de ese espíritu:

Conquistar el desarrollo y modernización económico nacional, basados en la justicia social, la democratización de la propiedad, el ingreso y la economía en su conjunto. ${ }^{50}$

De esta manera el FMLN, en su ideario, plantea explícitamente su apuesta por pasar de una democracia representativa -cuya característica fundamental es que la participación de la ciudadanía se reduce prácticamente a votar el día de las elecciones por ciudadanos que representarán sus intereses- a una democracia participativa, donde la ciudadanía tendría un rol más protagónico en las decisiones políticas. ¿Significa esto hacer una especie de Asamblea Legislativa ampliada o cabildos abiertos o referéndum? El ideario no lo especifica. Ni detalla mecanismos concretos encaminados a hacer funcional dicha propuesta.

Con respecto a la democracia "hacia dentro", lo primero en resaltar aquí es la manera de tomar decisiones al interior del partido. De acuerdo con el último de los principios, el partido de izquierda se autoconcibe como estrictamente democrático:

El FMLN está modelado y funciona como un Partido Democrático, de amplia base popular, participativo y fundamentado en la defensa de los intereses mayoritarios, en su pluralismo de izquierda, en su unidad programática y línea política. ${ }^{51}$

En esta línea se plantea que la toma de decisiones tendrá como generen acuerdos, o en todo caso se base razonamientos adecuados que

La adopción de las decisiones en el Partido exige: a) Razonables esfuerzos dedicados a construir decisiones unánimes o de consenso; b) Cuando no se logre unanimidad o el consenso, se aplicará el principio democrático de las decisiones por mayoría. ${ }^{52}$ 
Esa discusión tendrá como así se expresa a lo largo de muchos requisito indispensable el debate, artículos de los estatutos:

Respetar y promover en el Partido la libertad de expresión, de pensamiento y debate, ponderando las opiniones diferentes, evitando y combatiendo la intolerancia, la coacción política o laboral, la calumnia, la difamación, la falsedad, la cobardía política, los panfletos anónimos y la marginación o exclusión en razón de sus posiciones. ${ }^{53}$

En conclusión, cuando el FMLN se autodefinirse como un partido democrático, el debate tiene un peso preponderante. Así se expresa en las siguientes líneas del artículo doce:

El debate ideológico y teórico es indispensable al interior del Partido y estará dirigido a enriquecer y elevar la calidad de pensamiento y la práctica del FMLN. ${ }^{54}$

El debate es, pues, concebido como un mecanismo democrático que garantizaría la evolución del partido de izquierda sin perder de vista sus fundamentos teóricos y evitar así ser un partido sin democracia que pretende construir y defender un orden social democrático.
Con el tema de la participación femenina, a diferencia de ARENA, aparece recurrentemente en los estatutos, principios ideológicos y objetivos del partido ex combatiente. Es más, se tiene como una bandera de lucha importante el papel de la mujer en la construcción del socialismo:

Tomando en cuenta que las mujeres siendo más de la mitad de la población son víctimas de discriminación y violación a sus más elementales derechos por el hecho de ser mujeres. Y que esto se convierte en un obstáculo para cualquier proceso democrático y cualquier proyecto de desarrollo y principalmente para nuestro proyecto de sociedad socialista. ${ }^{55}$

En términos generales, el papel que pretende darle el FMLN a la mujer coincide con el discurso de igualdad de género. Incluso considera que el espacio de participación en la toma de decisiones, de acceso a cargos públicos y el respeto de la mujer en el interior del partido está hecho para la Comisión Nacional de la Mujer. ${ }^{56}$ 


\section{Conclusiones}

De la revisión de los idearios políticos de ARENA y el FMLN se puede agrupar las ideas esenciales de cada uno de la siguiente manera:

a) Las características fundamentales del ideario arenero son: defender todo tipo de libertades en un sistema no comunista ni socialista, por tanto, capitalista, en donde prime la libertad de empresa; concepción de un Estado en función de la superación individual y de respeto por la libre empresa; defender de toda amenaza a la nación salvadoreña, especialmente del comunismo, socialismo o marxismo internacional, por considerarse doctrinas que atentan contra los valores y principios democráticos, culturales y religiosos propios de occidente; por último, ser coherente con los postulados democráticos que se plantean para el país, lo que implica tener un funcionamiento interno que vaya en esa línea. Es decir, una democracia exige un partido democrático en su práctica interior.

b) Por el lado del FMLN, las características fundamentales de su ideario son: autodefinido ideológicamente como un partido político de izquierda revolucionaria, democrática y socialista, por tanto, anticapitalista, por ser el sistema capitalista irra- cional, anárquico y contrario al bien común; busca propiciar los cambios estructurales necesarios para la implantación del socialismo en la sociedad salvadoreña, debido a que ese sistema consiste en la igualdad política, económica y social; respecto a la concepción del Estado, éste debe ser equitativo en función de eliminar la explotación y la marginación; respeto por las creencias religiosas, valores y tradiciones propias de la idiosincrasia salvadoreña; ser un partido con funcionamiento interno "altamente" democrático: participativo, con discusiones, debates para la búsqueda de consensos; finalmente, sobre la democracia, se plantea que no sólo debe existir en el ámbito político, sino también en lo social y en lo económico, es decir, la igualdad y el acceso al poder debe traducirse en mejores condiciones de vida de la población.

Con todo, la cuestión que se abre con este análisis es: ¿qué tan fieles son los discursos, las propuestas de programas de gobierno, pero más esencial aún, las prácticas gubernamentales de quienes representan a estos partidos respecto de las ideas fundacionales antes descritas? Planteada la cuestión de forma más breve: ¿qué tanta fidelidad a estas ideas se da en la práctica? 
Todo apunta a una incoherencia en aspectos fundamentales. Considerando que ARENA Ileva ya en el espectro político salvadoreño más de 30 años y El FMLN como partido político en cargos públicos desde 1994, es válida la siguiente pregunta: ¿cuál es la realidad salvadoreña a pesar de la participación en el Estado de ambos partidos con tales ideales y principios?

Es evidente que en este país existen serias deficiencias en aspectos democráticos, se dan problemas graves de salud, de educación, de inseguridad pública, de vivienda, falta de solidez en instituciones públicas (impunidad, corrupción, ineficiencia, malversación de fondos, falta de acceso a la información pública, etc.), práctica antidemocrática de las cúpulas partidarias en relación de la nombramiento de candidatos a diputados, alcaldes o presidentes -sólo por citar un ejemplo-, inequidad de género, pobreza, desigualdad económica y lo más grave aún, que sintetiza todo lo anterior: la situación que violenta el cumplimiento irrestricto de los Derechos Humanos de la gran mayoría de la población salvadoreña. Todo ello hace que surja una crítica ineludible a partir de la dura realidad misma, no tanto a las ideas fundacionales de dichos partidos, sino a la falta de coherencia con las mismas. Si se hiciera un esfuerzo por cumplir la totalidad de ideas fundacionales, no hay duda que la realidad sería muy diferente a la actual. ${ }^{57}$

Así pues, con partidos incoherentes con sus mismos principios o ideas fundacionales, es difícil que se solucionen los problemas más graves del país desde el espacio político. El desafío es, por tanto, crear conciencia ciudadana para exigir otro tipo de partidos o que las personas líderes de los mismos se hagan a un lado si no se atreven a ser fieles y coherentes con sus mismos ideales políticos.

Notas

1 ARENA fue inscrito de manera oficial como partido político el 4 de diciembre de 1981; el FMLN, hasta el 1 de septiembre de 1992, antes había sido una organización político-guerrillera.

2 Esta contraposición de derecha-izquierda, al igual que otros elementos de sus idearios fundacionales no tiene una definición precisa. Se utiliza aquí como un juego de lenguaje aceptado por los líderes y la

mayoría de militantes de ambos partidos sin entrar en la discusión teórica que esto amerita.

3 ARENA, "Principios ideológicos y objetivos", ECA (396-397), octubrenoviembre, 1981, p. 1064.

$4 \quad$ Ibid.

5 Ibid.

$6 \quad$ Ibid., p. 1065. 
m 7 ARENA tilda así a todo aquel movimiento, partido o persona que proclame el marxismo como doctrina ideológica.

8 FMLN, Carta de principios, objetivos y estatutos, San Salvador, 2006, presentación.

$9 \quad$ Ibid., p. 1.

10 Ibid.

11 Ibid., p. 42.

12 Ibid., p. 44. Las cursivas son mías.

13 Ibid., p. 46.

14 FMLN, op. cit., p. 6.

15 Ramón Máiz, especialista en el tema del nacionalismo, plantea al menos dos tipologías de nacionalismo. En el ideario político de ARENA se ignora totalmente este tipo de estudios riguroso. Ver: Máiz, R., "Las ideologías nacionalistas contemporáneas: funcionalidad, estructura y tipología", en Mellón, J. A., Las ideas politicas en el siglo XXI, Ariel Ciencia Política, Barcelona, 2002; y Máiz, R. "Retos contemporáneos de la política: Los nacionalismos", en Águila, R., Manual de Ciencia Politica, Trotta, Madrid, 1997.

16 ARENA, Manual del activista, s/f, p. 16.

17 ARENA, Estatutos del partido, sin fecha, sin editorial. Documento disponible en CIDAI de la Biblioteca "Florentino Idoate, S.J.", p. 24.

18 ARENA, Manual del activista, s/f, p. 14.

19 ARENA, "Principios ideológicos y objetivos", en ECA (396-397), octubrenoviembre, 1981, p. 1064.

20 ARENA, Manual del activista, s/f, p. 4.

21 Cfr. ARENA, Manual del activista, s/f, p. 6.

22 Ibid.

23 ARENA, "Principios ideológicos y objetivos", en ECA (396-397), octubrenoviembre, 1981, p. 1064.

24 Ibid.

25 ARENA, Estatutos del partido, op. cit., p. 3.

26 Ibid

27 ARENA, "Principios ideológicos y objetivos", op. cit., p. 1064.

28 Ibid.

29 Ibíd., p. 1065.

30 Ibid., p. 1064.

31 FMLN, op. cit., p. 3.

32 Ibid., p. 43.

33 Cfr. FMLN, op. cit., p. 41.

34 Ibid., p. 46.

35 Ibid., p. 44

36 Ibid.

37 Ibid., p. 43.

38 Ibid., p. 42.

39 Ibid., p. 2.

40 ARENA, Estatutos del partido, op. cit., p. 3.

41 FMLN, op. cit., p. 42.

42 Ibid., p. 45.

43 ARENA, "Principios ideológicos y objetivos", p. 1064.

44 ARENA, Manual del activista, s/f, p. 4. Cursivas son mías.

45 ARENA, Estatutos del partido, op. cit., p. 24.

46 Cfr. ARENA, Ibid., p. 4.

47 ARENA, Manual del activista, s/f, p. 11. Cursivas son mías.

48 FMLN, op. cit., p. 44.

49 Ibid., p. 45. 
$50 \quad$ Ibid., p. 46.

51 Ibid., p. 4. Las cursivas son mías.

52 Ibid., p. 8.

53 Ibid., p. 7.

54 Ibid.

55 Ibid., p. 46.
56 Cfr. FMLN, op. cit., pp. 31-32.

57 Esta falta de coherencia con los mismos principios fundacionales criticada aquí a los partidos políticos, vale también para otro tipo de instituciones como las iglesias, universidades y empresas privadas. 